Pacific Journal of Mathematics

APPLICATIONS OF RANDOM FOURIER SERIES OVER
COMPACT GROUPS TO FOURIER MULTIPLIERS 


\title{
APPLICATIONS OF RANDOM FOURIER SERIES OVER COMPACT GROUPS TO FOURIER MULTIPLIERS
}

\author{
Alessandro Figà-Talamanca and J. F. Price
}

The Fourier series of a function on a compact group can be "randomized" by operating on each of the Fourier coefficients by independent random unitary operators. In this paper the theory of random Fourier series is used to prove several new results for a type of Rudin-Shapiro sequence and for Fourier multipliers. Thus in $\S 2$ it is shown in effect that $\mathfrak{M}\left(L^{p}, L^{q}\right) \subseteq \mathfrak{M}\left(L^{2}, L^{2}\right)$ for all $p, q \in[1, \infty]$ except for the pair $(p, q)=(\infty, 1)$, while in $\S 3$ the theory of random Fourier series is used to construct a type of Rudin-Shapiro sequence. This sequence is then used in $\S 4$ to obtain, for compact groups in one case, and compact Lie groups in another, slightly more restricted versions of several known families of strict inclusions for Fourier multipliers over compact Abelian groups.

1. Notation and preliminaries. Throughout this paper we suppose that $G$ is a compact group (always Hausdorff) with normalized Haar measure $\lambda_{G}$ and that $\Gamma$ is the set of equivalence classes of continuous irreducible unitary representations of $G$. The spaces of $p$-integrable functions, continuous functions and Radon measures over $G$ will be denoted by $L^{p}(G), C(G)$ and $M(G)$ [or $L^{p}, C$ and $M$ ] respectively, while their respective norms will be denoted by $\|\cdot\|_{p},\|\cdot\|_{\infty}$ and $\|\cdot\|_{M}$. We will identify each function with the measure which it generates.

If $\mu \in M(G)$, then $\mu$ is uniquely represented by the Fourier series

$$
\mu \sim \sum_{\gamma \in \Gamma} d(\gamma) \operatorname{tr}\left[\hat{\mu}\left(D_{r}\right) D_{\gamma}(\cdot)\right],
$$

where: $D_{r}$ is a representative (which we assume to be fixed throughout the sequel) of the class $\gamma \in \Gamma ; d(\gamma)$ is the (finite) dimension of $\gamma ; t r$ denotes the usual trace; and $\hat{\mu}$ is the Fourier transform of $\mu$ with respect to $\left\{D_{\gamma}: \gamma \in \Gamma\right\}$, that is

$$
\widehat{\mu}\left(D_{r}\right)=\int_{G} D_{r}(x)^{*} d \mu(x),
$$

for each $\gamma \in \Gamma, D_{\gamma}(x)^{*}$ denoting the Hilbert adjoint of $D_{r}(x)$.

Let $H_{r}$ denote the Hibert space of dimension $d(\gamma)$ corresponding to the representation $D_{\gamma}$, and let $\&$ denote the set consisting of functions $W$ on $\Gamma$ such that $W(\gamma)$ is an endomorphism of $H_{\gamma}$ for each $\gamma$. We can now define the "randomizing group" for $G$. Let $\mathscr{G}$ denote the product group $\prod_{r \in \Gamma} \mathscr{U}\left(H_{\gamma}\right)$, where $\mathscr{U}\left(H_{\tau}\right)$ is the compact group 
of unitary endomorphisms of $H_{\gamma}$. Clearly $\mathscr{G}$ may thought of as a subset of $\sqrt{5}$. Whenever $\mu \in M(G)$ and $U \in \mathscr{G}$ we denote the series

$$
\sum_{\gamma \in \Gamma} d(\gamma) \operatorname{tr}\left[\hat{\mu}\left(D_{r}\right) U(\gamma) D_{\gamma}\right]
$$

by $\mu^{U}$. The following two results are basic to this paper.

THEOREM 1.1. Suppose that $\mathscr{G}$ is equipped with its Haar measure and that $\mu \in M(G)$ has the property that $\mu^{U}$ represents a measure for every $U$ in a subset of $\mathscr{G}$ with positive measure; then $\mu$ is in $L^{2}(G)$.

Theorem 1.2. Suppose that $f \in L^{2}(G)$. Then $f^{U}$ is the Fourier series of a function in $\bigcap_{1 \leqq p<\infty} L^{p}(G)$ for almost every $U$ in $\mathscr{C}$, where $\mathscr{G}$ is equipped with its Haar measure.

The above two theorems are due to Figà-Talamanca and Rider (see [4, (36.18)] and [2] or [4, (36.5)]).

Multipliers 1.3. If $A$ and $B$ are any two spaces selected from $L^{p}(G), 1 \leqq p \leqq \infty, C(G)$ and $M(G)$, we define $\mathfrak{M}(A, B)$ to be the set of $W \in \mathbb{F}$ such that

$$
\sum_{\gamma \in \Gamma} d(\gamma) \operatorname{tr}\left[w(\gamma) \hat{\mu}\left(D_{r}\right) D_{r}\right]
$$

is the Fourier series of an element in $B$ (we will denote this element by $T_{W} \mu$ ) whenever $\mu$ belongs to $A$. Clearly the operator $\mu \mapsto T_{w} \mu_{a}$ is linear, while its continuity is an immediate consequence of the closed graph theorem. Thus we define a norm on $\mathfrak{M}(A, B)$ as the usual operator norm on the set $\left\{T_{W}: W \in \mathfrak{M}(A, B)\right\}$, and we denote this set by $M(A, B)$.

2. Multipliers and pseudomeasures. Let $\mathfrak{F}_{\infty}$ denote the subset of $[$ consisting of elements $W$ such that

$$
\|W\|_{\infty}=\sup \{\|W(\gamma)\|: \gamma \in \Gamma\}<\infty,
$$

where $\|W(\gamma)\|$ denotes the usual operator norm for endomorphisms of $H_{r}$. Whenever $G$ has the property that $\sup \{d(\gamma): \gamma \in \Gamma\}$ is finite [for example, if $G$ is Abelian] and $A, B$ are selected from $L^{p}(G), C(G)$ and $M(G)$, then it is banal to show that

$$
\mathfrak{M}(A, B) \subseteq \mathfrak{F}_{\infty},
$$

(see [4, Theorem (35.4), part IV]) and hence that each $T \in M(A, B)$ may be written in the form $T: f \mapsto f * \mu$, where $\mu$ is a pseudomeasure (see $[6, \S 2.2])$. 
The inclusion (2.1) is known to be valid for some pairs $A, B$ over an unrestricted compact group (see, for example, the table on pp. 410411 of Hewitt and Ross [4]) and in this section we extend its validity to some further pairs, thus completing five squares of Hewitt and Ross's table.

THeorem 2.1. Suppose that $(A, B)$ is one of the pairs $\left(L^{p}, L^{q}\right)$, $\left(L^{q}, L^{1}\right),\left(L^{q}, M\right),\left(L^{\infty}, L^{p}\right)$ or $\left(C, L^{p}\right)$ where $1<p<2<q<\infty$; then

$$
\mathfrak{M}(A, B)=\mathfrak{F}_{\infty} \text {. }
$$

REMARKS 2.2. (1) Four cases remain open: $\left(L^{\infty}, L^{1}\right),\left(L^{\infty}, M\right),\left(C, L^{1}\right)$ and $(C, M)$. We were not able to decide whether (2.1), and hence (2.2), is generally true for these cases. It is straightforward to show that $\mathfrak{M}\left(L^{\infty}, M\right)=\mathfrak{M}(C, M)=\mathfrak{M}\left(C, L^{1}\right)$. Also whenever $S \subseteq \Gamma$ has the property that $\sup \{d(\gamma): \gamma \in \Gamma\}=\infty$, it is not true that there exists $W \in\left[\mathfrak{F} \mid \mathfrak{F}_{\infty}\right.$ with supp $W \subset S$ such that $W \in \mathfrak{M}\left(C, L^{1}\right)$ (cf. Theorem (35.4), part V, of Hewitt and Ross [4]). For example, when $S$ is a $\Lambda(p)$ set for some $p>1$, Theorem 2.1 above applies to show that whenever $W \in \mathfrak{M}\left(C, L^{1}\right)$ has the property that supp $W \subseteq S$, then $W \in \mathfrak{F}_{\infty}$; examples are known of sets $S$ which are $\Lambda(p)$ for all $p>1$ and yet $\sup \{d(\gamma)$ : $\gamma \in S\}=\infty$ (see Remark 10 of [2] or (37.11) (a) of [4]).

(2) There can be no analogue of Theorem 2.1 for non-compact locally compact Abelian groups. For example, if $G$ is a non-compact $L C A$ group and $1 \leqq p<q \leqq \infty$, then there exists a multiplier operator from $L^{p}(G)$ into $L^{q}(G)$ which cannot be written as convolution with a pseudomeasure; see Larsen [5, Theorem 5.5.5].

Proof of 2.1. By inspection of Table (36.20) of [4], it is clear that to prove equality in (2.2) we need only show that $\mathfrak{M}(A, B) \subseteq \mho_{\infty}$. Suppose that $1<p<2<q<\infty$ and that $W \in \mathfrak{M}\left(L^{q}, M\right)$, that is, that $W \hat{f} \in \hat{M}$ for all $f \in L^{q}$. Since $2<q<\infty$, whenever $f \in L^{q}$, then

$$
\hat{f} U: \gamma \longmapsto \hat{f}\left(D_{r}\right) U(\gamma)
$$

is the Fourier transform of an $L^{q}$ function for a set of $U$ in $\mathscr{G}$ of measure 1 (Theorem 1.2). In this case $W \hat{f} U$ is the Fourier transform of a measure for all such $U$ and so, by Theorem 1.1, $W \hat{f}$ must be the Fourier transform of an $L^{2}$ function. Thus $W \in \mathfrak{M}\left(L^{q}, L^{2}\right)$ and since it is know that $\mathfrak{M}\left(L^{q}, L^{2}\right)=\mathfrak{M}_{\infty}[4]$, we have proved (2.2) for the pairs $\left(L^{q}, L^{p}\right),\left(L^{q}, L^{2}\right)$ and $\left(L^{q}, M\right)$.

If $\mathfrak{F}$ is a subset of $\mathfrak{F}$, write $\mathfrak{F}^{*}=\left\{W^{*}: W \in \mathfrak{F}\right\}$, where $W^{*}$ is defined by $\gamma \mapsto W(\gamma)^{*}$. Since we have just seen that $\mathfrak{M}\left(L^{q}, M\right)=\mathfrak{F}_{\infty}$ and since it is obvious that $\left(\mathfrak{F}_{\infty}\right)^{*}=\mathfrak{F}_{\infty}$, the proof of $(2.2)$ can be completed by showing 


$$
\mathfrak{M}\left(C, L^{q^{\prime}}\right) \subseteq \mathfrak{M}\left(L^{q}, M\right)^{*}
$$

However (2.3) is a simple consequence of the theory of adjoint operators. For if $W \in \mathfrak{M}\left(C, L^{q^{\prime}}\right)$ we can define $T_{W}^{*}: L^{q} \rightarrow M$ by

$$
\int_{G} \bar{g} d\left(T_{W}^{*} f\right)=\int_{G}\left(T_{W} g\right)^{-} f d \lambda_{G}
$$

for $f \in L^{q}, g \in C$. Thus, whenever $f \in L^{q}$ and $g$ is a trigonometric polynomial,

$$
\begin{aligned}
& \sum_{\gamma} d(\gamma) \operatorname{tr}\left[\hat{g}\left(D_{r}\right)^{*}\left(T_{W}^{*} f\right)^{\wedge}\left(D_{\gamma}\right)\right] \\
& \quad=\int_{G} \bar{g} d\left(T_{W}^{*} f\right)=\int_{G}\left(T_{W} g\right)^{-} f d \lambda_{G} \\
& \quad=\sum_{\gamma} d(\gamma) \operatorname{tr}\left[\left(T_{W} g\right)^{\wedge}\left(D_{\gamma}\right)^{*} \hat{f}\left(D_{\gamma}\right)\right] \\
& \quad=\sum_{\gamma} d(\gamma) \operatorname{tr}\left[\hat{g}\left(D_{\gamma}\right)^{*} W^{*}(\gamma) \hat{f}\left(D_{\gamma}\right)\right] .
\end{aligned}
$$

Thus $\left(T_{W}^{*} f\right)^{\wedge}\left(D_{\gamma}\right)=W^{*}(\gamma) \hat{f}\left(D_{\gamma}\right)$ for all $f$ in $L^{q}$ showing that $W^{*} \in$ $\mathfrak{M}\left(L^{q}, M\right)$, from which follows the required validity of (2.3).

We now look at the inclusion relation opposite to (2.1). The following simple proposition will describe exactly the cases when we have

$$
\mathfrak{F}_{\infty} \leqq \mathfrak{M}\left(L^{p}, L^{q}\right)
$$

Proposition 2.3. Suppose that $G$ is infinite; then the inclusion (2.4) is valid if and only if $q \leqq 2 \leqq p$.

Proof. (i) Il $q \leqq 2 \leqq p$, then $L^{q} \supseteqq L^{2} \supseteqq L^{p}$ and so $\mathfrak{M}\left(L^{p}, L^{q}\right) \supseteqq$ $\mathfrak{M}\left(L^{2}, L^{2}\right)$. However $\mathfrak{M}\left(L^{2}, L^{2}\right)=\mathfrak{F}_{\infty}$ and so (2.4) is satisfied.

(ii) On the other hand, suppose that $p<2$ and that (2.4) is valid. Then certainly $\mathscr{G} \subseteq \mathbb{M}\left(L^{p}, L^{q}\right)$ and a straightforward application of Theorem 1.1 implies that $L^{p} \subseteq L^{2}$, an absurdity when $G$ is infinite compact.

(iii) Finally we have the case $2<q \leqq \infty$ and $2 \leqq p \leqq \infty$. If we also suppose $q \neq \infty$, then

$$
\mathfrak{M}\left(L^{p}, L^{q}\right) \subseteq \mathfrak{M}\left(C, L^{q}\right) \subseteq \mathfrak{M}\left(L^{q^{\prime}}, M\right)^{*}
$$

by (2.3), and the proof proceeds as in paragraph (ii). The case $q=\infty$ follows easily from the inclusions.

$$
\mathfrak{M}\left(L^{p}, L^{\infty}\right) \subseteq \mathfrak{M}\left(L^{\infty}, L^{\infty}\right)=M(G)^{\wedge} \text {. }
$$

3. Rudin-Shapiro sequences. Let $G$ be a compact group and $t$ any number in $(2, \infty)$. By a Rudin-Shapiro sequence of type $t$ (briefly, a $t$-RS-sequence) we shall mean a sequence $\left(h_{n}\right)_{n \in N}$, where $N=\{1,2, \cdots\}$, 
of functions in $L^{t}(G)$ with the properties

$$
\left\{\begin{array}{l}
\inf \left\|h_{n}\right\|_{2}>0, \quad \sup \left\|h_{n}\right\|_{t}<\infty, \\
\lim \left\|\hat{h}_{n}\right\|_{\infty}=0 .
\end{array}\right.
$$

(Recall that by $\left\|\hat{h}_{n}\right\|_{\infty}$ we mean $\sup \left\{\left\|\hat{h}_{n}\left(D_{r}\right)\right\|: \gamma \in \Gamma\right\}$.)

When $t=\infty$ the above definition is essentially that of the RudinShapiro sequences discussed, for example, in Gaudry [3] (where it is shown that $\infty-R S$-sequences exist for all non-discrete locally compact Abelian groups) and in Edwards and Price [1, §5.4 and §§A.1-A.4] (where further sufficient conditions are given for the existence of $\infty-R S$-sequences). In this section we show that $t$ - $R S$-sequences, $t<\infty$, exist for all infinite compact groups. However, we would point out that the proof is completely existential in nature. Similarly to [1, $\S 5.4]$, it is easy to see that if $\left(h_{n}\right)$ satisfies (3.1), then we can construct a sequence $\left(k_{n}\right)$ from $\left(h_{n}\right)$ with the properties

$$
\left\{\begin{array}{l}
\left\|k_{n}\right\|_{t^{\prime}} \geqq B_{1} n \\
\left\|k_{n}\right\|_{s} \leqq B_{2}^{1 / s} n \\
\left\|\hat{k}_{n}\right\|_{\infty} \leqq 2^{-n},
\end{array} \quad\left(t^{\prime} \leqq s \leqq t\right)\right.
$$

where $B_{1}$ and $B_{2}$ are strictly positive numbers independent of $n$.

LEMMA 3.1. (a) Let $G$ be an infinite compact group and let $t \in$ $(2, \infty)$. Then there exists a Rudin-Shapiro sequence $\left(h_{n}\right)$ of type $t$. Without loss of generality we can take $\left(h_{n}\right)$ with $\left\|h_{n}\right\|_{2}=1$ for all $n \in N$.

(b) Moreover, if $G$ is also a Lie group, then there exists a second $t$-RS-sequence, $\left(h_{n}^{*}\right)$ say, with $\left\|h_{n}\right\|_{2}=\left\|h_{n}^{*}\right\|_{2}(=1), h_{n} * h_{n}^{*}=h_{n}^{*} * h_{n}$, and a positive nonzero number $\rho$ independent of $n$ such that

$$
\rho^{1+1 / p}\left\|\hat{h}_{n}\right\|_{\infty}^{2 / p} \leqq\left\|h_{n}^{*} * h_{n}\right\|_{p} \leqq\left\|\hat{h}_{n}\right\|_{\infty}^{2 / p},
$$

for all $n \in N$, and $1 \leqq p \leqq 2$.

REMARK 3.2. When $G$ is the circle group (the simplest compact Lie group) the original Rudin-Shapiro sequence $\left(\dot{\phi}_{n}\right)$ consists of trigonometric polynomials such that $\hat{\phi}_{n}$ takes only the values \pm 1 on its support $\left[0,2^{n}\right]$. One might suspect that in this case Lemma 3.1 (b) would be satisfied by taking $h_{n}=h_{n}^{*}=\phi_{n} /\left\|\phi_{n}\right\|_{2}$. Certainly (i) is satisfied (with $\rho=1$ ) but however (ii) is not since $\left\|\hat{h}_{n}\right\|_{\infty}^{2}=\left\|\phi_{n}\right\|_{2}^{-2}$, whereas

$$
\left\|h_{n}^{*} * h_{n}\right\|_{1}=\left\|\sum_{m=0}^{2^{n}} e^{i m x}\right\| /\left\|\phi_{n}\right\|_{2}^{-2} \sim \log 2^{n}\left\|\phi_{n}\right\|_{2}^{-2} \cdot
$$


This difference is not essential: by convolving the $n$th term of the classical Rudin-Shapiro sequence with the Fejér kernel of order $2^{n}$ one obtains sequences which, after normalizing, satisfy part (b) of the lemma. This depends on the fact that for $p>1$ Fejér kernel and the Dirichlet kernel have essentially the same $L^{p}$ norms. For our purposes Rudin-Shapiro sequences based on Fejér type kernels are more convenient.

Proof of 3.1. Let $\left(U_{n}\right)$ be a contracting sequence of open, nonvoid, symmetric, central (that is, stable under inner automorphisms of $G$ ) sets in infinite, compact $G$ with the property that $\lim _{n} \lambda_{G}\left(U_{n}\right)=0$. [When $G$ is also a Lie group we learn from (44.29) of [4] that there exists a number $k>0$ such that the $U_{n}^{\prime} s$ may be selected to also satisfy

$$
\left\{\begin{array}{l}
\lambda\left(U_{n}\right) \leqq k \lambda\left(U_{2 n}\right) \\
\left.U_{2 n} U_{2 n} \leqq U_{n}\right]
\end{array}\right.
$$

Define $\chi_{n}$ to be the characteristic function of $U_{n}$. Since each $U_{n}$ is central, the Fourier series of each $\chi_{n}$ has the form

$$
\chi_{n} \sim \sum_{r \in \Gamma} d(\gamma) \hat{\chi}_{n}\left(D_{\gamma}\right) \operatorname{tr}\left[D_{\gamma}\right],
$$

where the $\hat{\chi}_{n}\left(D_{\gamma}\right)$ are complex numbers. By the proof of Theorem 4 of [2] (which is Theorem 1.2 above), there exists a number $B(t)$, independent of $n$, and a subset $\mathscr{H}_{n}$ of $\mathscr{G}$ with measure 1 such that

$$
\left\|\chi_{n}^{W}\right\|_{t} \leqq B(t)\left\|\chi_{n}\right\|_{2}
$$

for all $W$ in $\mathscr{U}_{n}$. Since $G$ is compact, the measure of $\mathscr{U}_{n}^{-1}=\mathscr{U}_{n}^{*}$ is also 1 so that $\mathscr{C}_{n}$ and $\mathscr{U}_{n}^{*}$ have a nonvoid intersection. Thus corresponding to each $n$ we can, and will, choose $W_{n}$ in $\mathscr{U}_{n} \cap \mathscr{U}_{n}^{*}$.

Let $h_{n}=\lambda\left(U_{n}\right)^{-1 / 2} \chi_{n}^{W}$ and $h_{n}^{*}=\lambda\left(U_{n}\right)^{-1 / 2} \chi_{n}^{W_{n}^{*}}$. Then

$$
\left\|h_{n}\right\|_{2}=1, \sup _{n} \|\left. h_{n}\right|_{t} \leqq B(t)
$$

and

$$
\begin{aligned}
\left\|\hat{h}_{n}\right\|_{\infty} & =\lambda\left(U_{n}\right)^{-1 / 2} \sup _{r}\left\|\hat{\chi}_{n}\left(D_{r}\right) W_{n}(\gamma)\right\| \\
& =\lambda\left(U_{n}\right)^{-1 / 2}\left\|\hat{\chi}_{n}\right\|_{\infty} \leqq \lambda\left(U_{n}\right)^{-1 / 2}\left\|\chi_{n}\right\|_{1} \\
& =\lambda_{G}\left(U_{n}\right)^{1 / 2}
\end{aligned}
$$

Thus $\left(h_{n}\right)$ is a $t$-RS-sequence, and so is $\left(h_{n}^{*}\right)$ by similar reasoning.

Clearly $\left\|h_{n}\right\|_{2}=\left\|h_{n}^{*}\right\|_{2}=1$ and $h_{n}^{*} * h_{n}=h_{n} * h_{n}^{*}$ (since both convolutions have $\lambda\left(U_{n}\right)^{-1}\left(\chi_{n}\right)^{2}$ as their Fourier transforms), so that if $G$ is a Lie group we have only to prove (b) of 3.1. The right-hand inequality for $p=2$ is a trivial consequence of the fact that the norm of 
the operators $f \mapsto f * h_{n}$ from $L^{2}$ into $L^{2}$ is $\left\|\hat{h}_{n}\right\|_{\infty}$. To prove the lefthand inequality first note that $\left\|h_{n}^{*} * h_{n}\right\|_{p}=\lambda\left(U_{n}\right)^{-1}\left\|\chi_{n} * \chi_{n}\right\|_{p}$.

Suppose that the sequence $\left(U_{n}\right)$ is selected with the extra properties (3.3). Whenever $x \in U_{2 n}$,

$$
\begin{aligned}
\chi_{n} * \chi_{n}(x) & =\int_{U_{n}} \chi_{n}\left(y^{-1} x\right) d \lambda(y) \\
& \geqq \int_{U_{2 n}} \chi_{n}\left(y^{-1} x\right) d \lambda(y) \geqq \lambda_{G}\left(U_{2 n}\right) .
\end{aligned}
$$

because if $y \in U_{2 n}$ and $x \in U_{2 n}$, then $y^{-1} x \in U_{n}$. Therefore

$$
\begin{aligned}
& \int_{G}\left|\chi_{n} * \chi_{n}\right|^{p} d \lambda \geqq \int_{U_{2 n}}\left|\chi_{n} * \chi_{n}\right|^{p} d \lambda \\
& \geqq \lambda\left(U_{2 n}\right) \lambda\left(U_{2 n}\right)^{p} \geqq k^{p-1} \lambda_{G}\left(U_{n}\right)^{p+1} .
\end{aligned}
$$

Thus

$$
\left\|h_{n}^{*} * h_{n}\right\|_{p} \geqq \lambda\left(U_{n}\right)^{-1} k^{-(p+1) / p} \lambda\left(U_{n}\right)^{(p+1) / p} \geqq k^{-(1+1 / p)}\left\|\hat{h}_{n}\right\|_{\infty}^{2 p}
$$

(since $\left\|\hat{h}_{n}\right\|_{\infty} \leqq\left\|h_{n}\right\|_{1}=\left(U_{n}\right)^{1 / 2}$ ) as required for (i), where $\rho=k^{-1}$.

To complete the proof of 3.1 (b) we establish the following straightforward string of inequalities:

$$
\begin{aligned}
\left\|h_{n}^{*} * h_{n}\right\|_{1} & =\lambda\left(U_{n}\right)^{-1}\left\|\chi_{n}^{*} * \chi_{n}\right\|_{1} \\
& =\lambda\left(U_{n}\right)^{-1}\left\|\chi_{n}\right\|_{1}^{2}=\lambda\left(U_{n}\right)^{-1}\left(\int_{G} \chi_{n} d \lambda\right)^{2} \\
& =\lambda\left(U_{n}\right)^{-1}\left\|\hat{\chi}_{n}(I)\right\|^{2} \leqq \lambda\left(U_{n}\right)^{-1}\left\|\hat{\chi}_{n}\right\|_{\infty}^{2} \\
& =\lambda\left(U_{n}\right)^{-1}\left\|\hat{\chi}_{n} W_{n}\right\|_{\infty}^{2}=\left\|\hat{h}_{n}\right\|_{\infty}^{2},
\end{aligned}
$$

4. Strict inclusions for $\mathfrak{M}\left(L^{p}, L^{q}\right)$. In this section we use the existence of Rudin-Shapiro sequences of type $t, t<\infty$, to prove several strict inclusions for the spaces $\mathfrak{M}\left(L^{p}, L^{q}\right)$. In particular, our results will imply:

and then use interpolation.

4.1. If $p, q$ and $r$ belong to $[1, \infty]$ and satisfy $1 / p-1 / q \leqq 1-$ $1 / r$, then

$$
\|g * f\|_{q} \leqq\|g\|_{p}\|f\|_{r},
$$

whence we have, by considering the operators $g \mapsto g * f$,

$$
L^{r}(G)^{\wedge} \subseteq \mathfrak{M}\left(L^{p}, L^{q}\right)
$$

(where $L^{r}(G)^{\wedge}$ denotes the subset of $₹$ consisting of Fourier transforms of functions in $L^{r}(G)$ ). If furthermore $1<p \leqq q<\infty, p \neq q^{\prime}$ and $1<r \leqq \infty$, Theorem 4.3 below shows that the inclusion in (4.1) is strict whenever $G$ is infinite. 
4.2. If $G$ is a compact group, then

$$
\mathfrak{M}\left(L^{p_{1}}, L^{q_{1}}\right) \subseteq \mathfrak{M}\left(L^{p}, L^{p}\right)
$$

whenever $p_{1} \leqq p \leqq q_{1}$. If furthermore $G$ is an infinite compact Lie group and $2<p<q_{1}$, then Theorem 4.4 below will show that inclusion (4.2) is strict.

The above two results are essentially extensions to compact groups or compact Lie groups of results in Gaudry [3] and Edwards and Price $[1, \S 5]$ for locally compact Abelian groups; in fact we follow the broad outlines of the proofs used in [3].

THEOREM 4.3. Let $G$ be an infinite compact group and let $r$ belong to $(1, \infty]$. Then whenever $1<p \leqq q<\infty$ and $p \neq q^{\prime}$, there exist elements in $\mathfrak{M}\left(L^{p}, L^{q}\right)$ which are not in $L^{r}(G)^{\wedge}$.

Proof. Suppose that the hypotheses of the theorem are satisfied and that furthermore $\mathfrak{M}\left(L^{p}, L^{q}\right) \subseteq L^{r}(G)^{\wedge}$. By the closed graph theorem this imbedding is continuous so there exists a number $K$ such that for every function in $L^{u}(G)$, with $1-1 / u=1 / p-1 / q$ (see (4.1)), we have

$$
\|f\|_{r} \leqq K\left\|T_{f}\right\|_{p, q},
$$

where $\left\|T_{f}\right\|_{p, q}$ denotes the norm of the multiplier operator $g \mapsto g * f$ from $L^{p}$ into $L^{q}$. We will show that (4.3) is impossible.

There are two cases.

Case 1. $1 / p+1 / q<1$. In this case an application of the RieszThorin convexity theorem yields immediately that

$$
\left\|T_{f}\right\|_{p, q} \leqq\left\|T_{f}\right\|_{2,2}^{\alpha}\left\|T_{f}\right\|_{s^{\prime}, \infty}^{1-\alpha}
$$

where $1 / p=\alpha / 2+(1-\alpha) / s^{\prime}$ and $1 / q=\alpha / 2$. Since $\left\|T_{f}\right\|_{2,2}=\|\hat{f}\|_{\infty}$ and $\left\|T_{f}\right\|_{s^{\prime}, \infty}=\|f\|_{s}$, we have

$$
\text { || } T_{f}\left\|_{p, q} \leqq\right\| \hat{f}\|\|_{\infty}^{\alpha}\|f\|_{s}^{1-\alpha}
$$

with $\alpha=2 / q \neq 0$ and $1 / s=q(1-1 / q-1 / q) /(q-2) \neq 0$. Put $t=$ $\max \left\{u, s, r^{\prime}\right\}$; then $t \neq \infty$ and from $\S 3$ we know that there exists a sequence $\left(k_{n}\right)$ of $L^{t}$ functions satisfying (3.2). Substituting in (4.4) yields

$$
\left\|T_{k_{n}}\right\|_{p, q} \leqq \text { const. } 2^{-\alpha n} n^{1-\alpha}
$$

which tends to zero as $n$ tends to infinity since $\alpha \neq 0$.

On the other hand

$$
\left\|k_{n}\right\|_{r} \geqq\left\|k_{n}\right\|_{t^{\prime}} \geqq B_{1} n .
$$


Inequalities (4.5) and (4.6) together contradict (4.3) when $1 / p+1 / q<1$.

Case 2. $1 / p+1 / q>1$. A similar application of the convexity theorem yields

$$
\begin{aligned}
& \left\|T_{f}\right\|_{p q} \leqq\left\|T_{f}\right\|_{2,2}^{\alpha}\left\|T_{f}\right\|_{1, s}^{1-\alpha} \\
& \quad=\|\hat{f}\|_{\infty}^{\alpha}\|f\|_{s}^{1-\alpha}
\end{aligned}
$$

where $1 / p=\alpha / 2+1-\alpha, 1 / q=\alpha / 2+(1-\alpha) / s$ in which case $\alpha=$ $2 p^{\prime} \neq 0$ and $1 / s=p(1 / q+1 / p-1) /(2-p) \neq 0$. Inequality (4.3) may be contradicted in a manner similar to that of Case 1 by using a sequence satisfying (3.2), again with $t=\max \left\{u, s, r^{\prime}\right\}$.

THEOREM 4.4. Suppose that $G$ is an infinite compact Lie group and that $p_{0}, q_{0}, p_{1}, q_{1}(\varepsilon[1, \infty])$ have the properties that $p_{0} \leqq q_{0}, 1 / p_{0}+$ $1 / q_{0}<1, p_{1}<\infty$ and $q_{1} \geqq 2$. If furthermore $q_{1}>q_{0}$, then there exist elements in $\mathfrak{M}\left(L^{p_{0}}, L^{q_{0}}\right)$ which are not in $\mathfrak{M}\left(L^{p_{1}}, L^{q_{1}}\right)$.

This result remains valid when $\mathfrak{M}\left(L^{p_{0}}, L^{q_{0}}\right)$ is replaced by $\mathfrak{M}\left(L^{q_{0}^{\prime}}\right.$, $\left.L^{p_{0}^{\prime}}\right)$ and/or $\mathfrak{M}\left(L^{p_{1}}, L^{q_{1}}\right)$ is replaced by $\mathfrak{M}\left(L^{q_{1}^{\prime}}, L^{p_{1}^{\prime}}\right)$.

Proof. Suppose that $G$ and $p_{0}, q_{0}, p_{1}, q_{1}$ satisfy the hypotheses of the theorem. By arguing as in the proof of Theorem 4.3 it is clear that the result may be proved by finding a sequence $\left(h_{n}\right)$ of functions such that

$$
\min \left\{\left\|T_{h_{n}}\right\|_{p_{1}, q_{1}},\left\|T_{h_{n}}\right\|_{q_{1}^{\prime}, p_{1}^{\prime}}\right\} / \max \left\{\left\|T_{h_{n}}\right\|_{p_{0}, q_{0}},\left\|T_{h_{n}}\right\|_{q_{0}^{\prime}, p_{0}^{\prime}}\right\} \rightarrow \infty
$$

as $n \rightarrow \infty$.

Let $\left(h_{n}\right)$ and $\left(h_{n}^{*}\right)$ denote a pair of $t$-RS-sequences satisfying Lemma 3.1 (b) with $t$ equal to the maximum of $p_{1},\left(q_{0}-2\right) / q_{0}\left(1-1 / q_{0}-1 / p_{0}\right)$ and $\left(2-q_{0}^{\prime}\right) / q_{0}^{\prime}\left(1-1 / q_{0}-1 / p_{0}\right)$. Then, by proceeding as in the proof of Theorem 4.1, we have

$$
\max \left(\left\|T_{h_{n}}\right\|_{p_{0}, q_{0}},\left\|T_{h_{n}}\right\|_{q_{1}^{\prime}, p_{0}^{\prime}}\right) \leqq \text { const. }\left\|\hat{h}_{n}\right\|_{\infty}^{2 / q_{0}} \text {. }
$$

On the other hand we have, by the definition of the norms,

$$
\left\|T_{h_{n}}\right\|_{p_{1}, q_{1}} \geqq\left\|h_{n}^{*} * h_{n}\right\|_{q_{1}} /\left\|h_{n}^{*}\right\|_{p_{1}}
$$

and

$$
\left\|T_{i_{n}}\right\|_{q_{1}^{\prime}, p_{1}^{\prime}}=\left\|T_{h_{n}}^{\prime}\right\|_{p_{1}, q_{1}} \geqq\left\|h_{n} * h_{n}^{*}\right\|_{q_{1}} /\left\|h_{n}^{*}\right\|_{p_{1}},
$$

where $T_{h_{n}}^{\prime}$ is the operator $f \mapsto h_{n} * f$ (see the discussion in 5.3 of [1]). Thus

$$
\min \left(\left\|T_{h_{n}}\right\|_{p_{1}, q_{1}},\left\|T_{h_{n}}\right\|_{q_{1}^{\prime}, p_{1}}\right) \geqq\left\|h_{n}^{*} * h_{n}\right\|_{q_{1}} /\left\|h_{n}^{*}\right\|_{p_{1}} \text {. }
$$

Now it is easily shown that if $g \in L^{q_{1}}$ with $q_{1} \geqq 2$, then 


$$
\|g\|_{2}^{2} \leqq\|g\|_{1}^{\beta}\|g\|_{q_{1}}^{(1-\beta) q_{1}} \text { where } 2=\beta+(1-\beta) \cdot q_{1},
$$

and so

$$
\left\|h_{n}^{*} * h_{n}\right\|_{q_{1}} \geqq\left\|h_{n}^{*} * h_{n}\right\|_{2}^{2 / q_{1}^{\prime}}\left\|h_{n}^{*} * h_{n}\right\|_{1}^{-1+2 / q_{1}} \text {. }
$$

Applying 3.1 (b), (4.10) and the definition of a $t$-RS-sequence yields

$$
\begin{aligned}
\min \left(\left\|T_{h_{n}}\right\|_{p_{1}, q_{1}}\left\|T_{h_{n}}\right\|_{q_{1}^{\prime}, p_{1}^{\prime}}\right) \geqq & \left(\rho^{3 / 2}\left\|\hat{h}_{n}\right\|_{\infty}\right)^{2 / p_{1}^{\prime}}\left(\rho\left\|\hat{h}_{n}\right\|_{\infty}\right)^{-2+4 / q_{1}}\left\|h_{n}^{*}\right\|_{n}^{-1} \\
& \geqq A\left\|\hat{h}_{n}\right\|_{\infty}^{2 / q_{1}},
\end{aligned}
$$

where $A$ is a non zero positive mumber. This inequality combines with (4.8) to show that (4.7) is satisfied whenever $q_{1}>q_{0}$ since $\left\|\hat{h}_{n}\right\|_{\infty} \rightarrow 0$ as $n \rightarrow \infty$.

COROLlARY 4.5. Theorem 4.4 (and hence also 4.2) remains valid for compact group $G$ which have a closed normal subgroup $G_{0}$ such that $G / G_{0}$ is an infinite (compact) Lie group.

REMARKS 4.6. (i) We do not know whether Theorem 4.4 remains valid for all compact groups or, for that matter, whether part (b) of Theorem 3.1 remains valid in the general case. We should remark that the construction of Rudin-Shapiro sequences for compact Abelian groups is more complicated for groups which do not have a torus as a factor group; see Gaudry [3].

(ii) In the notation of [4], $G$ has the property of Corollary 4.5 if and only if there exists a finite subset $\gamma_{1}, \cdots, \gamma_{k}$ of $\Gamma$ such that $\left[\gamma_{1}, \cdots \gamma_{k}\right]$ is infinite. This follows from (28.10) and (28.6) of [4] combined with the fact that a compact group $G$ is a Lie group if and only if its dual $\Gamma$ is finitely generated.

Proof of 4.5. Suppose that $G_{0}$ is a closed normal subgroup of $G$ and that $\Gamma_{0}$ is the dual (hypergroup) of $G / G_{0}$. Let $A_{0}=A\left(\Gamma, G_{0}\right)$ denote the annihilator of $G_{0}$ in $\Gamma$; then there exists an isomorphism $\varphi$ between hypergroups $A_{0}$ and $\Gamma_{0}$ in such a manner that for each $\gamma \in A_{0}$ we can choose $D_{\varphi(r)}$ so that

$$
D_{\varphi(\gamma)} \circ \pi=D_{\gamma},
$$

where $\pi$ denotes the natural projection from $G$ onto $G / G_{0}$. For the sequel we suppose that the $D_{\varphi(r)}$ are chosen in this manner. Thus, for example, if $f$ is an integrable function on $G / G_{0}$ and

$$
f \sim \sum_{\gamma_{0} \in \Gamma_{0}} d\left(\gamma_{0}\right) \operatorname{tr}\left[\hat{f}\left(D_{\gamma_{0}}\right) D_{r_{0}}\right],
$$

then 


$$
f \circ \pi \sim \sum_{r \in A_{0}} d(\gamma) \operatorname{tr}\left[\hat{f}\left(D_{\varphi(r)}\right) D_{r}\right]
$$

For each $\mu \in \mathfrak{S}\left(\Gamma_{0}\right)$, we define $\mu^{\prime} \in \mathfrak{S}(\Gamma)$ by $\mu^{\prime}=\mu \circ \varphi$ on $A_{0}$, and zero otherwise. Corollary 4.5 is an immediate consequence of Theorem 4.4 and the fact that $\mu \in \mathfrak{M}\left(L^{p}\left(G / G_{0}\right), L^{q}\left(G / G_{0}\right)\right)$ if and only if $\mu^{\prime} \in$ $\mathfrak{M}\left(L^{p}(G), L^{q}(G)\right)$. The proof of this final equivalence is routine. (For example, see Lemma 4.6 of [3]; use can also be made of equations of the form (4.11) above and (A.3) (A.5) and (A.6) in the appendix of [1]).

Added in proof. The authors have been able to show that Theorem 4.4 (and hence also 4.2) are valid for an unrestricted compact group. The proof will appear elsewhere.

\section{REFERENCES}

1. R. E. Edwards and J. F. Price, A naively constructive approach to boundedness principles, with applications to harmonic analysis, L'Enseignement Mathématique, 16 (1970), 255-296.

2. Alessando Figà-Talamanca and Daniel Rider, A theorem of Littlewood and lacunary series for compact group. Pacific J. Math., 16 (1966), 505-514.

3. Garth I. Gaudry, Bad behavior and inclusion results for multipliers of type $(p, q)$, Pacific J. Math., 35 (1970), 83-94.

4. Edwin Hewitt and Kenneth A. Ross, Abstract Harmonic Analysis, Volume II. Springer-Verlag, Berlin (1970).

5. Ronald Larsen, An Introduction to the Theory of Multipliers, Springer-Verlag Berlin (1971).

6. J. F. Price, Some strict inclusions between spaces of $L^{p}$ multipliers, Trans. Amer. Math. Soc., 152 (1970), 321-330.

Received August 3, 1971. Research of the second-named author supported by a C.N.R. fellowship (Comitato Nazionale per la Matematica).

UNIVERSITY OF GENOA,

GenoA, ItALy 



\section{PACIFIC JOURNAL OF MATHEMATICS}

\section{EDITORS}

\author{
H. SAMELSON \\ Stanford University \\ Stanford, California 94305 \\ C. R. HOBBY \\ University of Washington \\ Seattle, Washington 98105
}

\author{
J. DugundJI \\ Department of Mathematics \\ University of Southern California \\ Los Angeles, California 90007
}

\author{
RICHARD ARENS \\ University of California \\ Los Angeles, California 90024
}

\section{ASSOCIATE EDITORS}
E. F. BECKENBACH
B. H. NeumanN
F. WOLF
K. YoSHIDA

\section{SUPPORTING INSTITUTIONS}

\author{
UNIVERSITY OF BRITISH COLUMBIA \\ CALIFORNIA INSTITUTE OF TECHNOLOGY \\ UNIVERSITY OF CALIFORNIA \\ MONTANA STATE UNIVERSITY \\ UNIVERSITY OF NEVADA \\ NEW MEXICO STATE UNIVERSITY \\ OREGON STATE UNIVERSITY \\ UNIVERSITY OF OREGON \\ OSAKA UNIVERSITY
}

\author{
UNIVERSITY OF SOUTHERN CALIFORNIA \\ STANFORD UNIVERSITY \\ UNIVERSITY OF TOKYO \\ UNIVERSITY OF UTAH \\ WASHINGTON STATE UNIVERSITY \\ UNIVERSITY OF WASHINGTON \\ $* * * *$
$*$
AMERICAN MATHEMATICAL SOCIETY
NAVAL WEAPONS CENTER
}

The Supporting Institutions listed above contribute to the cost of publication of this Journal, but they are not owners or publishers and have no responsibility for its content or policies.

Mathematical papers intended for publication in the Pacific Journal of Mathematics should be in typed form or offset-reproduced, (not dittoed), double spaced with large margins. Underline Greek letters in red, German in green, and script in blue. The first paragraph or two must be capable of being used separately as a synopsis of the entire paper. The editorial "we" must not be used in the synopsis, and items of the bibliography should not be cited there unless absolutely necessary, in which case they must be identified by author and Journal, rather than by item number. Manuscripts, in duplicate if possible, may be sent to any one of the four editors. Please classify according to the scheme of Math. Rev. Index to Vol. 39. All other communications to the editors should be addressed to the managing editor, Richard Arens, University of California, Los Angeles, California, 90024.

50 reprints are provided free for each article; additional copies may be obtained at cost in multiples of 50 .

The Pacific Journal of Mathematics is published monthly. Effective with Volume 16 the price per volume (3 numbers) is $\$ 8.00$; single issues, $\$ 3.00$. Special price for current issues to individual faculty members of supporting institutions and to individual members of the American Mathematical Society: $\$ 4.00$ per volume; single issues $\$ 1.50$. Back numbers are available.

Subscriptions, orders for back numbers, and changes of address should be sent to Pacific Journal of Mathematics, 103 Highland Boulevard, Berkeley, California, 94708.

PUBLISHED BY PACIFIC JOURNAL OF MATHEMATICS, A NON-PROFIT CORPORATION

Printed at Kokusai Bunken Insatsusha (International Academic Printing Co., Ltd.), 270, 3-chome Totsuka-cho, Shinjuku-ku, Tokyo 160, Japan. 


\section{Pacific Journal of Mathematics}

\section{Vol. 43, No. 2 \\ April, 1972}

Arne P. Baartz and Gary Glenn Miller, Souslin's conjecture as a problem on the real line....................................... 277

Joseph Barback, On solutions in the regressive isols ............... 283

Barry H. Dayton, Homotopy and algebraic K-theory ................ 297

William Richard Derrick, Weighted convergence in length ............ 307

M. V. Deshpande and N. E. Joshi, Collectively compact and semi-compact sets of linear operators in topological vector spaces ............. 317

Samuel Ebenstein, Some $H^{p}$ spaces which are uncomplemented in $L^{p} \ldots . .327$

David Fremlin, On the completion of locally solid vector lattices ......... 341

Herbert Paul Halpern, Essential central spectrum and range for elements of

a von Neumann algebra............................... 349

G. D. Johnson, Superadditivity intervals and Boas' test ............. 381

Norman Lloyd Johnson, Derivation in infinite planes . . . . . . . . . . . 387

V. M. Klassen, The disappearing closed set property .............. 403

B. Kuttner and B. N. Sahney, On the absolute matrix summability of Fourier series ........................................... 407

George Maxwell, Algebras of normal matrices................... 421

Kelly Denis McKennon, Multipliers of type $(p, p) \ldots \ldots \ldots \ldots \ldots \ldots . . \ldots 29$

James Miller, Sequences of quasi-subordinate functions ............. 437

Leonhard Miller, The Hasse-Witt-matrix of special projective varieties ..... 443

Michael Cannon Mooney, A theorem on bounded analytic functions ...... 457

M. Ann Piech, Differential equations on abstract Wiener space .......... 465

Robert Piziak, Sesquilinear forms in infinite dimensions ............. 475

Muril Lynn Robertson, The equation $y^{\prime}(t)=F(t, y(g(t))) \ldots \ldots \ldots \ldots .483$

Leland Edward Rogers, Continua in which only semi-aposyndetic

subcontinua separate ............................... 493

Linda Preiss Rothschild, Bi-invariant pseudo-local operators on Lie

groups ...................................... 503

Raymond Earl Smithson and L. E. Ward, The fixed point property for

arcwise connected spaces: a correction ...................... 511

Linda Ruth Sons, Zeros of sums of series with Hadamard gaps .......... 515

Arne Stray, Interpolation sets for uniform algebras............... 525

Alessandro Figà-Talamanca and John Frederick Price, Applications of random Fourier series over compact groups to Fourier multipliers .. 